Chirurgia (2021) 116: 524-532

No. 5, September - October

Copyright@ Celsius

http://dx.doi.org/10.21614/chirurgia.116.5.524

\title{
latrogenic Bile Duct Injuries: A Critical Appraisal of Classification Systems
}

\author{
Dimitrios Symeonidis, Dimitrios Zacharoulis, Alexandros Diamantis, Athina A. Samara*, Dimitrios E. Magouliotis, \\ Theodoros Floros, Konstantinos Tepetes
}

Department of Surgery, University Hospital of Larissa, Larissa, Greece

${ }^{*}$ Corresponding author: Athina A. Samara, MD, MSc Department of Surgery University Hospital of Larissa Larissa, Greece, 41110 Tel.: +302413501701

Fax: +302413501559

E-mail: at.samara93@gmail.com

\section{Rezumat}

Leziunile iatrogene ale căilor biliare: o analiză critică a sistemelor de clasificare

Leziunile căilor biliare reprezintă cele mai dramatice complicații ale colecistectomiei deschise sau laparoscopice. Efectele negative asupra calității vieții pacientului şi supraviețuirii generale sunt cele mai evidente consecințe ale unor astfel de leziuni. $\mathrm{O}$ strategie de tratament eficientă după localizarea precisă a tipului de leziune reprezintă singura metodă de a preveni aceste consecințe morbide. În încercarea de a descrie şi clasifica cu acuratețe leziunile căilor biliare, au fost propuse mai multe sisteme de clasificare. Întrebarea critică este dacă avem cu adevărat nevoie de toate aceste sisteme şi dacă fiecare dintre aceste sisteme adaugă valoare bazei de cunoştințe existente sau complică şi mai mult domeniul. Fiecare sistem de clasificare are mai multe avantaje pe care îşi bazează utilitatea clinică, dar implică şi o serie de limitări. În prezent, o abordare personalizată în care sistemul de clasificare oferă cele mai adecvate recomandări - fie în ceea ce priveşte diagnosticul, fie în stabilirea tratamentului - pare a fi cea mai justificată opțiune.

Cuvinte cheie: clasificare, iatrogenic, leziuni de căi biliare, management, diagnostic

\section{Abstract}

Bile duct injuries represent the most dramatic complications after an open or laparoscopic cholecystectomy. The detrimental effects on 
patient quality of life and overall survival are the most obvious consequences of such injuries. An effective treatment strategy after accurate mapping of the injury type is the only method of averting these morbid consequences. Several classification systems have been proposed in an attempt to accurately describe and categorize bile duct injuries. The critical question is whether we truly need all these systems and whether each of these systems adds value to the existing knowledge base, or further obscures the field. Each classification system has several advantages to base its clinical utility on, but entails a reasonable number of limitations as well. Currently, a tailored approach adopting the classification system which provides the most appropriate guidance - either in terms of diagnosis or treatment decision making - appears to be the most justified option.

Key words: categorize, iatrogenic, bile duct injuries, management, diagnosis

\section{Introduction}

Bile duct injuries represent the most dramatic complications after an open or laparoscopic cholecystectomy. Following the introduction of laparoscopic cholecystectomy as the surgical treatment of choice for symptomatic cholelithiasis, the number of iatrogenic bile duct injuries increased significantly. Studies indicate the rise in incidence of bile duct injuries after laparoscopic cholecystectomy to be as high as $1 \%$, with a reasonable estimate being 1 in 1000 cases (0.1\%) (1). The detrimental effects on the patient's quality of life and even on overall survival are the adverse consequences of such injuries. An effective treatment strategy after accurate mapping of the injury type represents the only method of averting these morbid consequences. At present, it is unanimously agreed that a valid classification system and accurate description of the type of the injury is necessary to provide the best treatment available in an effective manner. Throughout the years several classification systems have been proposed aiming to tally each injury type with the most proper intervention, to assess and compare the results of certain interventions between institutions, and to offer a safe map for preventing such injuries.

In addition to the type of the injury itself, there are other factors which can influence the results of a certain treatment strategy. Literature reports have highlighted the impor- tance of the timing of the repair, the overall condition of the patient and the experience in hepatobiliary surgery when performing the repair as important prognostic factors regarding the success of the repair (2-3). The purpose of the present report is to perform a critical appraisal of existing classification systems, highlighting the advantages as well as the disadvantages of each classification. Supporting clinicians to choose to adapt one classification system over another in a specific clinical setting was the primary goal of the present review.

\section{Classification Systems}

\section{Bismuth Classification}

Several classification systems have been proposed in an attempt to accurately describe and categorize bile duct injuries. Before the widespread use of laparoscopic cholecystectomy, the vast majority of bile duct injuries involved strictures of the common bile duct. These injuries occurred either early in the postoperative course due to direct narrowing of the common bile duct as a result of inappropriately placed hemostatic sutures, or were delayed as a result of collateral thermal damage to the extrahepatic biliary tree while utilizing electrocautery to achieve hemostasis in close proximity to the common bile duct. The classification proposed by Bismuth in 1982 was almost universally adopted by the surgical community, as it could efficiently categorize these types of injuries (3). This 
classification system includes five types of bile duct injuries. The distance of the injury, and more specifically of the stricture from the confluence of the right and left bile duct, was the main determinant of each injury type.

According to this classification, a type I injury involves the common bile duct or the most distant part of the common hepatic duct, at least $2 \mathrm{~cm}$ from the hepatic duct confluence. A type II injury involves the proximal part of the common hepatic duct (less than $2 \mathrm{~cm}$ from the confluence). A type III injury encompasses a hilar injury leaving no part of the common hepatic duct intact, sparing however the ceiling of the bile duct confluence. Type IV classification is an injury involving the common bile duct bifurcation in total. Finally, type $\mathrm{V}$ lesions are strictures of the hepatic duct associated with a stricture on a separate aberrant right branch. Although the intended use of this classification was for established strictures, it has been occasionally used in the literature to describe bile duct injuries in the acute setting as well, such as for bile leaks. The rationale behind this classification is to aid the surgeon in deciding on the most appropriate type of reconstruction based on the availability for anastomosis of healthy biliary mucosa.

\section{Strasberg Classification}

The accumulation of new types of bile duct injuries mainly associated with laparoscopic cholecystectomy rendered the Bismuth classification in part obsolete and to a significant degree inadequate. As such, Strasberg et al. proposed a new classification (Fig. I) which incorporated the already established Bismuth classification while also including new bile duct injury patterns (mainly bile leaks) encountered frequently after the advent of laparoscopic cholecystectomy (4). Table 1 presents a summary of the Strasberg classification in comparison with the Bismuth classification.

\section{McMahon Classification}

In 1995, McMahon et al. proposed another classification of bile duct injuries (5). The authors stratified bile duct injuries into minor and major injuries based on the associated treatment or reconstruction, in case where a surgical intervention was warranted. Common bile duct or cystic duct - common bile duct junction lacerations involving less than $25 \%$ of the duct circumference were classified as minor injuries. Conversely, lacerations of more than $25 \%$ of the common bile duct circum-
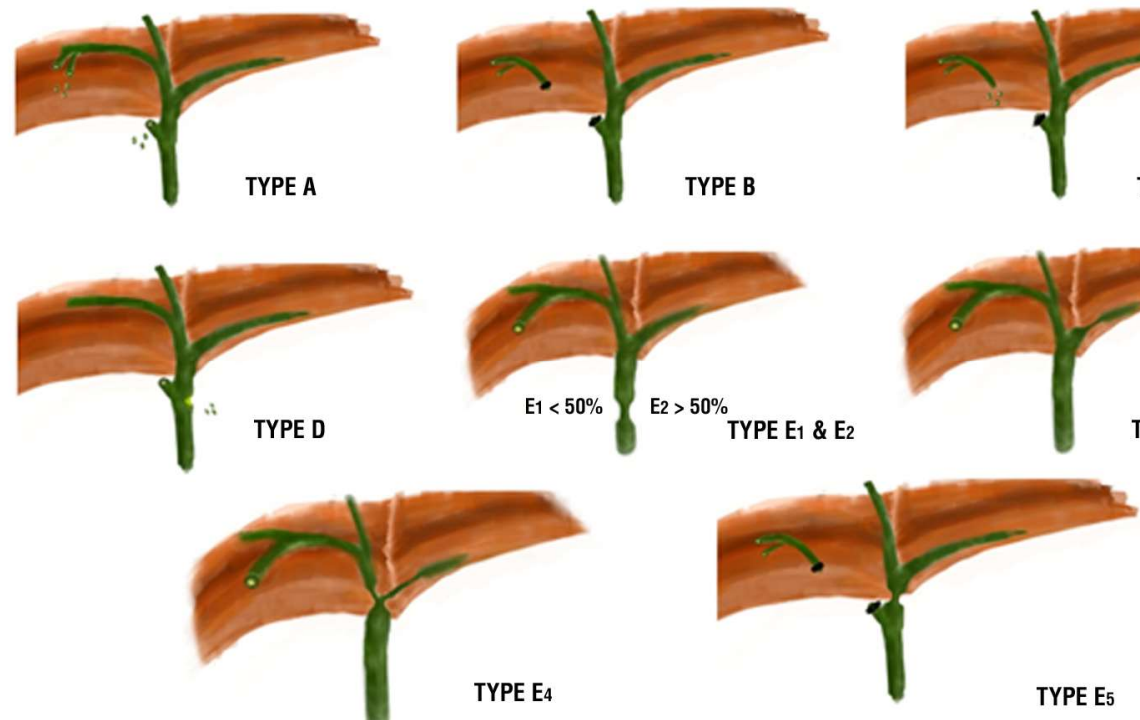

Figure 1. Strasberg classification of bile duct injuries and strictures
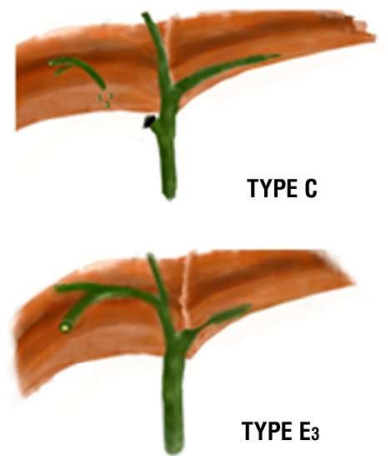

TYPE E5 
Table 1. A summary of the Strasberg classification in comparison with the Bismuth classification

\begin{tabular}{lcc}
\hline Bile duct injury & Bismuth & Strasberg \\
\hline $\begin{array}{l}\text { Cystic duct leak or leaks from small ducts } \\
\text { in liver bed }\end{array}$ & - & A \\
\hline Occlusion of an aberrant right hepatic duct & - & B \\
\hline Leak from an aberrant right hepatic duct & - & C \\
\hline $\begin{array}{l}\text { Lateral injury to the common bile duct } \\
(<50 \% \text { of the circumference })\end{array}$ & - & D \\
\hline Common hepatic duct stricture, stump $>2 \mathrm{~cm}$ & Type I & E1 \\
\hline Common hepatic duct stricture, stump $<2 \mathrm{~cm}$ & Type II & E2 \\
\hline Hilar stricture with preserved biliary confluence & Type III & E3 \\
\hline Hilar stricture with involvement of confluence & Type IV & E4 \\
\hline $\begin{array}{l}\text { Stricture to an aberrant right hepatic duct and } \\
\text { to common hepatic duct }\end{array}$ & Type V & E5 \\
\hline
\end{tabular}

ference, reaching up to the level of total transection and the development of a bile duct stricture in the postoperative setting were classified as major injuries. As was the case with the previous classifications, the authors emphasized the complexity of the management of bile duct strictures compared with bile leaks.

\section{Steward Way Classification}

A rather different approach was used by Way et al. which aimed to analyze in depth the major bile duct injuries during laparoscopic cholecystectomy (6). The analysis was conducted on records of 252 patients with major bile duct injuries which included operation notes, pathology reports, radiology reports, operative x-rays, postoperative x-rays, and 22 unedited videotapes of laparoscopic cholecystectomies. Determining the causes of the injuries and the circumstances contributing to them were the actual challenges. The injuries were analyzed under the prism of human error analysis. Errors were then further categorized into misperception errors, errors due to faulty decision making, and errors due to the level of the surgeon's skill. In summary, injuries were classified into four groups based on the mechanism and the anatomy of the injury (Fig. 2).

Class I injuries (7\% of cases) involved a laceration of the common bile duct, which was not however a complete transection of the duct. These injuries occurred either because the common bile duct was mistakenly identified as the cystic duct (72\%), but the mistake was recognized early enough to avert a complete transection of the duct, or because of an inappropriately oriented incision on the cystic duct extending incorrectly onto the common bile duct. Such incisions were made to accommodate the cholangiogram catheter whenever an intraoperative cholangiogram was performed (28\%). Concomitant arterial injury of the adjacent right hepatic artery normally lying beneath the common bile duct was noted in one of all class I injuries (5\%).

Class II injuries ( $22 \%$ of cases) consisted of a lateral injury to the common hepatic duct that resulted in stricture formation and/or a biliary fistula, while never resulting in the complete transection or the total occlusion of the common bile duct. These injuries were usually provoked due to the placement of clips on the duct, or due to thermal damage of the duct during attempts to control bleeding with the use of electrocautery (23\%), or as a result of poor exposure (68\%). An anatomic variance regarding the right hepatic artery origin (i.e., from the superior mesenteric artery) was recorded in two patients and may have contributed to the injury. In six cases (9\%) biliary strictures were the result of a common bile duct of normal size exploration and the subsequent T-tube placement. The right hepatic artery was injured in $18 \%$ of these cases.

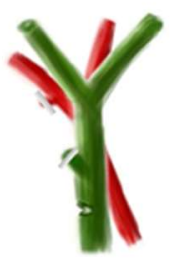

Class I

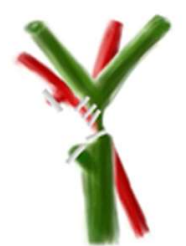

Class II
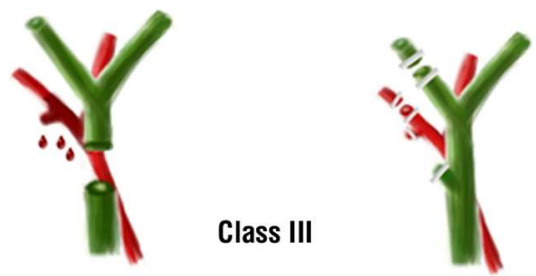

Class IV

Figure 2. Steward-Way Classification 
Class III injuries were the most common ( $61 \%$ of cases) and involved the complete transection of the common bile duct along with the excision of a variable portion of the duct proximal to the first transection, commonly including the cystic duct-common bile duct junction. These injuries occurred because the common bile duct was mistaken for the cystic duct. These patients were further subdivided based on the proximal extent of the injury as follows: class IIIa, 104 patients (68\%) who had an intact remnant of common hepatic duct; class IIIb, 27 patients (18\%) had the common hepatic duct transected at the level of the bifurcation; class IIIc, 16 patients (10\%) had the bifurcation excised as well; and class IIId, 6 patients $(4 \%)$ where the transection line was above the first bifurcation of at least one of the lobar ducts. In 31 cases $(20 \%)$ the proximal end of the transected hepatic duct was clipped while in the remaining 122 cases it was left open leading to bile leak. A concomitant injury to the right hepatic artery was recorded in $27 \%$ of class III injuries.

Class IV injuries (10\% of cases) involved damage either in the form of transection or a lateral injury to the right hepatic duct. In $60 \%$ of cases, there was an injury to the right hepatic artery as well. Class IV injuries occurred because the right hepatic duct was mistaken for the cystic duct (64\%), or from a lateral injury to the right hepatic duct during deep dissection in Calot's triangle (36\%). The injuries involved: the main right lobar duct (68\%), a segmental duct (28\%), both (4\%), and a segmental duct and the common hepatic duct $(12 \%)$.

\section{Bergman Classification}

Bergman et al. proposed another classification after studying 53 patients with bile duct injuries after laparoscopic cholecystectomy treated in the Amsterdam Academic Medical center (7). Four types of ductal injuries were identified. Type A (18 patients) injury involved a bile leakage from the cystic duct or peripheral hepatic radicles, type B (11 patients) injury was considered a major bile duct leakage, type C (9 patients) injury was an isolated ductal stricture, while type D (15 patients) injuries were classified as the complete transections of the common or hepatic bile duct.

\section{Hannover Classification}

Bektas et al. assessed results after surgical intervention (laparoscopic cholecystectomy) for iatrogenic bile duct lesions in 74 consecu- $^{-}$ tive patients at a tertiary referral center; as a result, a new classification system called the Hannover classification was proposed (Fig. 3) (8). In the Hannover classification, the authors divided bile duct injuries into five main categories. Type A is peripheral bile leakage either for the cystic duct (A1) or a leak for the gallbladder bed (A2) with established connection to the main bile duct system. Type B injury refers to a stricture of the main duct injury, for example due to an inappropriately placed clip causing either incomplete (B1) or complete (B2) duct obstruction. Type $\mathrm{C}$ is a tangential injury of the common bile duct. Type C injuries are further subdivided into the following categories based on the type and location of the injury: $\mathrm{C} 1$ - small punctiform lesion less than $5 \mathrm{~mm}$ in length; $\mathrm{C} 2$ - extensive lesion more than $5 \mathrm{~mm}$ in length located below the bifurcation; C3 - extensive lesion at the level of the bifurcation; and $\mathrm{C} 4$ - extensive lesion above the level of bifurcation. These injuries can also be accompanied by arterial or vein injuries involving the right hepatic artery (d), the left hepatic artery (s), the proper hepatic artery ( $p$ ), the common hepatic artery (com), the cystic artery (c), or the portal vein (pv).

Type D is an injury where a total transection of the common hepatic duct has occurred. Further categorizations of type D lesions were made according to the location of the injury and whether there was a defect in the main duct. A D1 categorization is an injury without a main duct defect below the bifurcation, a D2 categorization is an injury with a defect below the bifurcation, D3 categorization is an injury with or without a defect at the level of the bifurcation, while a $\mathrm{D} 4$ categorization is an injury with or without a defect above the bifurcation. Every single one of these injury 

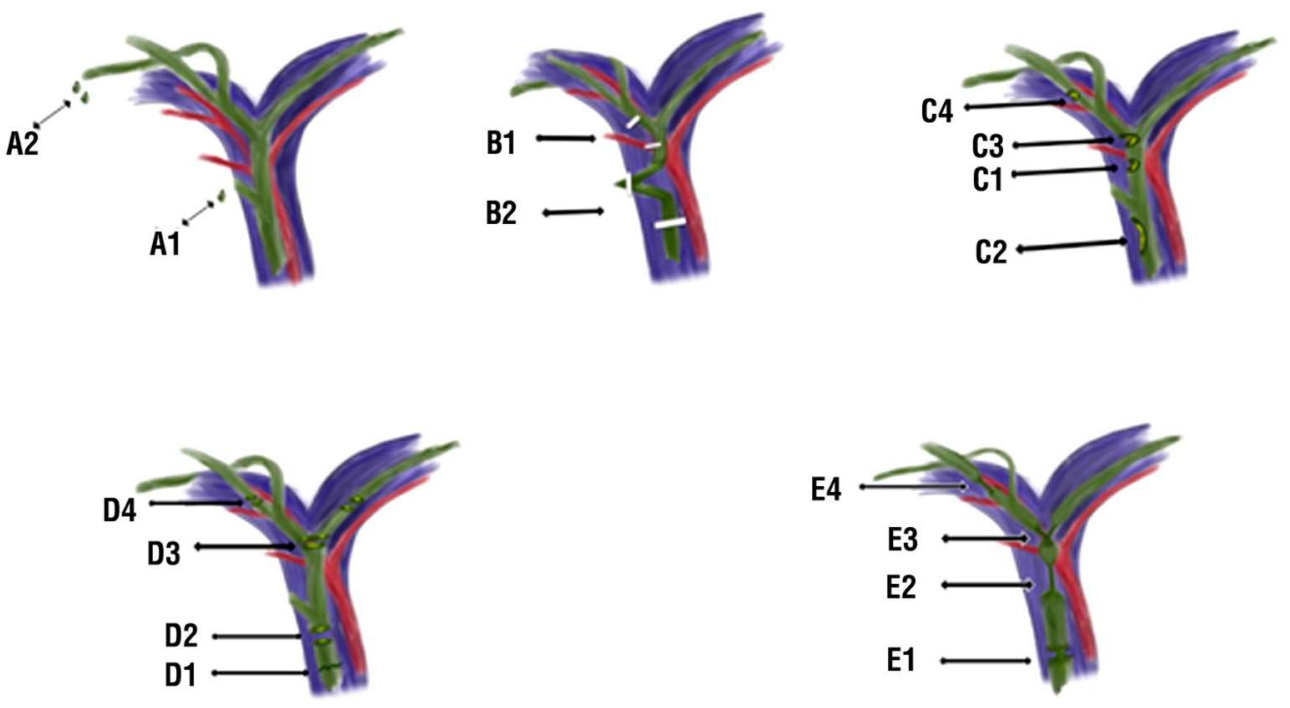

Figure 3. Hannover Classification

patterns could be accompanied by an arterial or vein injury as described for type $\mathrm{C}$ injuries. Finally, type $\mathrm{E}$ injuries are main bile duct strictures in the form of a short circular less than $5 \mathrm{~mm}$ stricture of the main duct (E1), or of a longitudinal more than $5 \mathrm{~mm}$ in length stricture of the main duct (E2). The stricture might also involve the bifurcation (E3) or the right main duct (E4). The same regarding concomitant arterial injuries also apply for type E injuries.

\section{Critical Appraisal of Classification Systems}

It is clear that the presence of multiple classification systems leads to notable confusion when the stratification of an iatrogenic bile duct injury is the case. Diagnosing and accurately classifying an injury, deciding on the proper management plan, and objectively assessing the results of a certain intervention could possibly be compromised within this framework. In an attempt to organize the classification systems into a single report and ultimately perform a comparison between them, it becomes obvious that each working group which addressed the challenge of bile duct injuries adopted by definition a preexisting classification, or even proposed a novel classification. The critical question is whether we truly need all these systems and whether each of these systems adds value to the existing knowledge base, or further obscures the field. Each classification system has several advantages to base its clinical utility upon, but entails a reasonable number of limitations as well.

Most of the previously mentioned classification systems were mainly elaborated on the basis of retrospective analysis of different cohorts of bile duct injury patients. The authors of each classification attempt categorized their given patient sample so that different prognostic patient groups (in terms of morbidity or regarding the treatment required) could be yielded. The different characteristics of these distinct patient samples in terms of sample size or regarding the distribution of the variable injury types within a small patient sample represent an obvious limitation in all of the available classifications. For example, the Amsterdam classification as proposed by Bergman et al. was based on the categorization of only 53 bile duct injury patients treated in the Amsterdam Academic Medical center (7). Apart from this innate selection bias in almost all of the classification attempts, the significantly 
important role of a concomitant arterial or venous injury along with the injury in the main duct system was disregarded during initial classification attempts. Studies showed that the presence of such injuries to the adjacent vessels could possibly complicate and undermine the reconstruction success rates; this could increase the anastomotic stricture rate, but most importantly the coexistence of the two injuries could affect the extent of the required surgical intervention $(9,10)$. However, every single classification has undoubted advantages, which are further augmented and highlighted when utilized under appropriate and well-defined conditions.

The classification proposed by Bergman et al., which is quite popular among endoscopists, practically assesses the role of endoscopic retrograde cholangiopancreatography (ERCP) in the diagnosis and treatment of bile duct injuries depending on the type (7). Based on the analysis of a relatively small patient sample, ERCP established the diagnosis in all type $\mathrm{A}, \mathrm{B}$, and $\mathrm{C}$ injuries according to the Bergman classification. However, in type D lesions a percutaneous transhepatic cholangiography (PTC) was utilized to assess the proximal biliary tree and the actual extent of the injury. The endoscopic approach was chosen and proved adequate as a standalone treatment in 16 out of 18 patients with type A lesions, in five out of seven patients with type $\mathrm{B}$ lesions, and in three out of nine patients with a type $\mathrm{C}$ injury. Although a surgical intervention was ultimately required in cases where the endoscopic management failed, it was the primary intervention in all type $D$ injuries.

Similarly, the McMahon classification draws the line between minor and major bile duct injuries on the basis of complexity of the proper treatment (5). The presence of one of the following features, for example laceration of more than $25 \%$ of the common bile duct circumference, a complete transection of the common bile duct or the common hepatic duct or the development of a postoperative bile duct stricture renders an injury as major. Minor injuries are usually injuries amenable to endo- scopic treatment associated with a good overall prognosis, while major injuries usually require a surgical reconstruction via a procedure highly associated with short- and longterm morbidity. Consequently, the clinical scenario where the endoscopic treatment addresses the issue of a bile duct injury effectively is determined in detail by both the Bergman and McMahon classifications.

On the other hand, in the case of a bile duct injury not fulfilling the indications for a successful endoscopic treatment, information not included in the Bergman and McMahon classifications is almost always required. The surgical repair of a bile duct injury - either in the form of stricture or a complete transection of the common bile duct, or the common hepatic duct-includes most commonly a hepaticojejunostomy, or occasionally an end-to-end anastomosis of the common bile duct stumps over a $\mathrm{T}$ or $\mathrm{Y}$ tube. A favorable outcome of a hepaticojejunostomy can be anticipated in the majority of patients, however, complications usually in the form of postoperative stricture formation are not negligible. Studies raise the incidence of delayed stricture formation to as high as $38 \%(9-11)$. The presence of a concomitant arterial injury, the presence of a non-dilated proximal biliary system and anastomosing electrocautery damaged stumps have been implicated in the occurrence of anastomotic site stricture (12).

In this setting, the Strasberg classification which completely incorporates the previously proposed classification by Bismuth, appeared as ideal when it was first introduced (3-4). Both of these classifications of biliary strictures are based on the lowest level of the extrahepatic biliary tree in which healthy biliary mucosa is available for anastomosis. The rationale of these classifications is to help the surgeon decide on the appropriate technique for the repair. More specifically, a type I Bismuth or E1 Strasberg injury where the common hepatic duct stump is longer than 2 $\mathrm{cm}$, can be repaired without extending the anastomosis to the left duct and/or lowering the hilar plate. Type II Bismuth or E2 Strasberg strictures with a stump shorter 
than $2 \mathrm{~cm}$ in length usually require the opening of the anterior wall of the left hepatic duct while preserving the posterior wall of the bifurcation, according to the Hepp-Couinaud technique for a wide enough anastomosis (13). Lowering the hilar plate is not usually necessary, but it may drastically improve exposure in some cases.

Type III Bismuth or E3 Strasberg lesions, which spare the ceiling of the biliary confluence, require lowering of the hilar plate and extending the anastomosis towards the left ductal system. Type IV Bismuth or E4 Strasberg lesions involve the biliary confluence in total and require either reconstruction or multiple anastomoses. Finally, Type V Bismuth or E5 Strasberg lesions are strictures of the hepatic duct associated with a stricture on a separate aberrant right branch. In this case, the branch should be included in the repair. Therefore, both of these classifications, especially the one proposed by Strasberg, can provide the required guidance regarding the technical consideration of the repair technique. The main disadvantage of these classifications, however, is that they did not take into account possible vascular injuries that could accompany bile duct injuries, which could have a significant impact on the extent of the surgical intervention which may be required, and, ultimately, an adverse effect on the overall prognosis of these patients.

Conversely, the Steward Way classification, which is increasingly utilized and adopted by the most recent reports, appears more reliable in terms of injury type description than the previous classifications (6). Way et al. primarily aimed to determine the causes of the bile duct injuries occurring during laparoscopic cholecystectomy, the circumstances contributing to them, and to analyze the injuries under the prism of human error analysis. The subcategories of type III injuries accost the surgical perspective adequately and in a similar manner with the Bismuth and Strasberg classifications. Furthermore, they complement the latter with acute phase complications (i.e., bile leaks) and with the possible vascular injuries often encountered in conjunction to the bile duct injuries. As the rationale behind this classification was not to guide surgical decision making regarding the technique to be followed, a practical surgical treatment guide is lacking. In addition, it appears less descriptive regarding lesions at the level of bifurcation and, moreover, usually requires a completely different operative approach. However, the main advantage of this classification compared with the others is that it can provide insight into the reasons for the injury itself. Avoiding such injuries in the future and auditing surgeons within a service quality assessment scheme are best addressed by this classification (14-15).

A more elaborated approach was followed by Bekta et al. in 2007 when they proposed the Hannover classification (8). The authors demonstrated a significant association between specific, classifiable injury patterns, and the different surgical treatments that have been employed in each case scenario. The final result was a classification system with numerous injury patterns; more than 20 patterns were identified in the patient sample studied. The authors aligned with numerous reports highlighting in detail the importance of possible vascular involvement, along with the significance of the exact location of the bile duct injury, (for example at the level of bifurcation or above the bifurcation) on the extent of surgical intervention especially regarding the resection of the bifurcation or the required extent of hepatic resection (9-13). While this is the most detailed classification available, it has proven rather difficult to use in everyday clinical practice, limiting its wide acceptance in the surgical community. Furthermore, many of the subcategories enlisted in the Hannover classification cannot be diagnosed and discriminated easily in the preoperative setting using imaging studies altering the surgical approach.

\section{Conclusions}

In conclusion, an ideal classification system should be simple and descriptive with significant prognostic correspondence. It 
should also provide guidance regarding the proper therapeutic interventions and achieve high levels of penetration and acceptance among institutions. Despite the fact that there are several existing classification systems of iatrogenic bile duct injuries, at present a single system fulfilling all of these ideal requirements does not exist. Currently, a tailored approach adopting the classification system which provides the most appropriate guidance - either in terms of diagnosis or treatment decision making - appears to be the most justified option.

\section{Conflict of Interest}

The authors have no conflict of interest to declare.

\section{References}

1. Archer SB, Brown DW, Smith CD, Branum GD, Hunter JG. Bile duct injury during laparoscopic cholecystectomy: results of a national survey. Ann Surg. 2001;234(4):549-58; discussion 558-9.

2. Pesce A, Portale TR, Minutolo V, Scilletta R, Li Destri G, Puleo S. Bile duct injury during laparoscopic cholecystectomy without intraoperative cholangiography: a retrospective study on 1,100 selected patients. Dig Surg. 2012;29(4):310-4.

3. Bismuth $\mathrm{H}$, Majno PE. Biliary strictures: classification based on the principles of surgical treatment. World J Surg. 2001;25(10):1241-4.

4. Strasberg SM, Hertl M, Soper NJ. An analysis of the problem of biliary injury during laparoscopic cholecystectomy. J Am Coll Surg. 1995;180(1): $101-25$.

5. McMahon AJ, Fullarton G, Baxter JN, O'Dwyer PJ. Bile duct injury and bile leakage in laparoscopic cholecystectomy. Br J Surg. 1995;82(3):307-13.

6. Way LW, Stewart L, Gantert W, Liu K, Lee CM, Whang K et al. Causes and prevention of laparoscopic bile duct injuries: analysis of 252 cases from a human factors and cognitive psychology perspective. Ann Surg. 2003; 237(4):460-9.

7. Bergman JJ, van den Brink GR, Rauws EA, de Wit L, Obertop H, Huibregtse $\mathrm{K}$, et al. Treatment of bile duct lesions after laparoscopic cholecystectomy. Gut. 1996:38(1):141-7.

8. Bektas H, Schrem H, Winny M, Klempnauer J. Surgical treatment and outcome of iatrogenic bile duct lesions after cholecystectomy and the impact of different clinical classification systems. Br J Surg. 2007;94(9): 1119-27.

9. Tzovaras G, Dervenis C. Vascular injuries in laparoscopic cholecystectomy: an underestimated problem. Dig Surg. 2006;23(5-6):370-4.

10. Schmidt SC, Settmacher U, Langrehr JM, Neuhaus P. Management and outcome of patients with combined bile duct and hepatic arterial injuries after laparoscopic cholecystectomy. Surgery. 2004;135(6):613-8.

11. Johnson SR, Koehler A, Pennington LK, Hanto DW. Long-term results of surgical repair of bile duct injuries following laparoscopic cholecystectomy. Surgery. 2000;128(4):668-77.

12. Al-Ghnaniem R, Benjamin IS. Long-term outcome of hepaticojejunostomy with routine access loop formation following iatrogenic bile duct injury. $\mathrm{Br}$ J Surg. 2002;89(9):1118-24

13. Myburgh JA. The Hepp-Couinaud approach to strictures of the bile ducts. I. Injuries, choledochal cysts, and pancreatitis. Ann Surg. 1993;218(5): 615-20.

14. Pesce A, Palmucci S, La Greca G, Puleo S. latrogenic bile duct injury: impact and management challenges. Clin Exp Gastroenterol. 2019;12: 121-128.

15. Pulitanò C, Parks RW, Ireland H, Wigmore SJ, Garden OJ. Impact of concomitant arterial injury on the outcome of laparoscopic bile duct injury. Am J Surg. 2011;201(2):238-44. 